\title{
RETROSPECTIVE ASSESSMENT OF ORAL HEALTH OF URBAN INDIAN ADULTS USING INTRAORAL CAMERA: CROSS-SECTIONAL STUDY
}

\section{Vimal Arora ${ }^{1}$}

1. Lt Gen (Dr) Vimal Arora (Retd) BDS, MDS, FDS RCPS (Glasgow)

PVSM, AVSM, VSM \& Bar, OSRE(Oman), Chief Clinical Officer, Clove Dental

\section{Corresponding Author:}

Lt Gen (Dr) Vimal Arora (Retd) BDS, MDS, FDS RCPS (Glasgow)

PVSM, AVSM, VSM \& Bar, OSRE (Oman)

Chief Clinical Officer, Clove Dental

RK Khanna Tennis Stadium, DLTA Complex,

Africa Avenue, New Delhi, India, Pin :110029

Former Director General Dental Services, Army Dental Corps

Former Member of Dental Council \&Hony Dental Surgeon to President of India

E-mail ID : vimalaroravsm@gmail.com

\begin{abstract}
:
Objective: To determine the oral health status of the adult population of the country residing in the urban regions of India.

Material and Methods: Data from oral examinations of 7,783 adults who presented themselves in oral health screening and awareness camps at 18 major regions of North and South India was analyzed to obtain the prevalence of periodontal disease in the adult population of the country. Prevalence of periodontal disease alongwith indicators of periodontal disease like presence of stains, calculus, mobility were studied in adults of 18 years and above.
\end{abstract}

Results: The prevalence of periodontal disease was found to be $63.09 \%$ in the study population with no significant difference between males and females.

Conclusion: There is a high prevalence of periodontal disease among the urban adult population. Intraoral camera can be used as an effective tool in the diagnosis of periodontal disease and also as a device for oral health education and tele-dentistry.

Keywords: Prevalence of periodontal disease, Oral hygiene status, Intraoral camera, Tele-dentistry, Oral hygiene education 


\section{INTRODUCTION}

Periodontal disease is one of one the most common oral health problem and when left untreated frequently leads to tooth loss. This in turn, can lead to poor appearance, dysfunction, loss of function, pain and even decreased self-esteem. Several studies have been conducted in different parts of the world to estimate the prevalence of periodontal diseases. However, the last National Oral Health Survey, which assessed the burden of periodontal disease along with other dental problems in India was conducted about two decades ago. Since then, various regional and risk group specific studies have been performed in different regions however they were unable to provide a clear estimate of the periodontal condition of the Indian adults residing in major cities of the country.

In the era of technological advancement in healthcare, digital dentistry devices like the intraoral camera are being used across the world for detection of dental diseases. The intraoral camera was first introduced in the 1980s. It a portable handheld device which is easy to operate, inexpensive and can produce high quality oral images for assessment by the dentist." The intraoral camera can also be used as a device for 'tele-dentistry', i.e., in situations where a specialist is not available, an intra-oral camera can be used to send high quality images via the internet to the specialist for consultation.

This study thus aimedto assess the oral hygiene status of the adult population of the country by utilizing the intraoral camera as the diagnostic tool.

\section{MATERIALS AND METHODS}

This retrospective, observational, crosssectional study was formulated from data obtained by oral examinations of individuals from June 2019 to December 2019. Oral examinations of more than 15,000 individuals were performed by trained dentists at various dental screening and awareness camps set up in several cities of North and South India, namely, Delhi NCR, Hyderabad, Bengaluru and Chennai. Dental awareness camps were organized at locations like residential areas, corporate offices etc.

A sample of 7,783 individuals was included in the study, which was obtained from oral examinations of more than 15,000 individuals at various dental screening and awareness camps conducted at several locations in the urban regions of the country. Out of the 7,783 individuals who were included in the study, 6,139 were males and 1,643 were females. Adults of all ages 18 and above who gave consent for oral examinationwere included in this study. Individuals who did not give consent were excluded from the study. Ethical clearance to conduct this study was given by internal ethical Committee.

All examinations were performed by trained dentists using intraoral cameras. Sterilization was achieved by covering the tip of the intraoral camera with a disposable cellophane sheet, which was changed following each examination. The images were manipulated for best contrast and color and were displayed to the person being inspected to make them aware of their oral hygieneconditions. Assessment for periodontal disease was made purely on visual examination and the individual judgement of the concerned trained dentists who carried the examinations at various locations. All individuals who displayed visual signs of periodontal disease like red and swollen gums, recession, mobilityand generalized calculus deposition were diagnosed to have periodontal disease.

\section{RESULTS}

Table 1 shows the gender distribution of the study participants. $77.44 \%$ of the study participants were males whereas $22.56 \%$ were females.

Table 1. Gender Distribution of study participants

\begin{tabular}{|c|c|c|}
\hline Gender & $\mathbf{N}$ & $\mathbf{\%}$ \\
\hline Male & 6139 & 78.89 \\
\hline Female & 1643 & 21.11 \\
\hline Total & 7783 & 100.00 \\
\hline
\end{tabular}

Table 2 shows the prevalence of periodontal problems in the study population. The prevalence of Periodontal Problems was found to be $63.09 \%$ in the study population. Prevalence of males suffering from one or the other form of periodontal problems was $63.55 \%$ whereas in females this number was found to be $61.55 \%$.

Table 2. Distribution of dental conditions based on gender of study subjects

\begin{tabular}{|c|c|c|c|c|}
\hline \multirow{2}{*}{ Gender } & \multicolumn{2}{|c|}{$\begin{array}{c}\text { Individual with } \\
\text { Periodontal Problems }\end{array}$} & \multicolumn{2}{|c|}{$\begin{array}{c}\text { Dentally Heathy } \\
\text { Individual }\end{array}$} \\
\cline { 2 - 5 } & $\mathbf{N}$ & $\%$ & $\mathbf{N}$ & $\%$ \\
\hline Male & 3995 & 65.07 & 1628 & 26.51 \\
\hline Female & 1087 & 66.15 & 381 & 23.18 \\
\hline Total & 5082 & 65.30 & 2009 & 25.81 \\
\hline N = Number of Individuals & \multicolumn{4}{|l}{} \\
\hline
\end{tabular}




\section{DISCUSSION}

It is surprising to see that only fewpopulation-based studies have been conducted in India reporting the prevalence of periodontal diseases in the generalpopulation. Most of the studies that are conducted report prevalence of periodontal diseases either in small regions of the country in in specific age-groups or risk groups like pan and tobacco chewers, diabetics, HIV patients, psychiatric patients etc., $5,6,8$ These studies may be able to depict the burden of periodontal diseases in specific age-groups, regions and certain sections of the society, but their results do not paint a clear picture of the burden of periodontal disease on the entire nation. Also, no studies have yet been performed in India that assess the prevalence of periodontal disease using an intraoral camera. The intraoral camera has the merit of easy sterilization, re-usability and portability. This study was thus planned to estimate the prevalence of periodontal problems in the urban population of the entire country using an intraoral camera and to compare theprevalence of periodontal disease among males and females.

The current study analyses data obtained from oral examinations of 7,783 individuals conducted at several dental screening and awareness camps over a period of 6 months across various parts of the country using intraoral cameras. $77 \%$ of the individuals who gave consent for examination were males and 23\% were females. 5,082 individuals out of the study population of 7,782 were suffering from some form of periodontal disease, i.e. the prevalence of periodontal problems in the present study was found to be $65.30 \%$. Mehta R et al. (2015) have reported a prevalence of around $77 \%$ in West Bengal with almost equal distribution among males and females. Our study has somewhat similar findings with comparable prevalence of periodontal disease in males and females at $65.07 \%$ and $66.15 \%$ respectively. The difference in prevalence rates between the two studies may be because the current study was constructed using data from oral examinations performed in multiple regions of North and South India and not just a single state or region. Also, all other studies have been performed with conventional methods using mirrors and CPI probes as opposed to our study which has utilized the intraoral camera for assessment of periodontal status of the study population. With the use of the intraoral camera dentists while performing oral examinations were able to educate the study participants about their oral hygiene status with increased efficiency and at same time with greater ease.

\section{CONCLUSION}

It is alarming to see that $65 \%$ of Indian adults residing in the urban regions of India are suffering from one or the other form of periodontal problem. The people residing in the urban areas have considerably better access to oral health services than those in the rural regions of the country. When such a poor status of oral hygiene exists in the urban regions, it is worrying what the status of oral hygiene would be in the rural,underserved regions of the nation. The current study encourages the use of intraoral camera for the detection of dental diseases, as it is reliable, efficient, portable and can also aid effectively in imparting oral health education to the people.In addition, it can be used as a means of 'teledentistry' to obtain consultation from a specialist by way of high-quality images which can be sent over the internet.

\section{REFERENCES}

1. Benjamin VR. Surgeon general's perspectives. Public Health Reports. 2010 Dec;125(1):2.

2. Khan SA, Omar H. Tele-dentistry in practice: literature review. Telemedicine and e-Health. 2013 Jul 1;19(7):565-

3. Pentapati KC, Siddiq H. Clinical applications of intraoral camera to increase patient compliance-current perspectives. Clinical, cosmetic and investigational dentistry. 2019;11:267.

4. Avula H. Tele-periodontics-Oral health care at a grass root level. Journal of Indian Society of Periodontology. 2015 Sep;19(5):589.

5. Sumanth S, Bhat KM, Bhat GS . Periodontal health status in pan chewers with or without the use of tobacco. Oral health \& preventive dentistry. 2008 Jun $1 ; 6(3)$.

6. Kumar A, Pandey MK, Singh A, Mittra P, Kumar P. Prevalence and severity of periodontal diseases in type 2 diabetes mellitus of Bareilly region (India). Int $\mathrm{J}$ Med Sci Public Health. 2013 Jan 1;2(1):7783. 
7. Ranganathan K, Magesh KT, Kumarasamy N, Solomon S, Viswanathan R, Johnson NW. Greater severity and extent of periodontal breakdown in 136 south Indian human immunodeficiency virus seropositive patients than in normal controls: a comparative study using community periodontal index of treatment needs. Indian Journal of Dental Research. 2007 Apr 1;18(2):55.

8. Kumar M, Chandu GN, Shafiulla MD. Oral health status and treatment needs in institutionalized psychiatric patients: one year descriptive cross sectional study. Indian journal of dental research. 2006 Oct $1 ; 17(4): 171$.

9. Mehta R, Kundu D, Chakrabarty S, Bharati P. Periodontal conditions and treatment in urban and rural population of West Bengal, India. Asian Pacific Journal of Tropical Medicine. 2010 Feb 1;3(2):152-7. 